\title{
Design and Performance Test of Large-Scale Cryopump Used in Space Environment Simulation System
}

\author{
Y.S.ZHAO, R.P.SHAO, L.C.SUN, W.SUN, Y.WANG, G.H.REN, Z.LI \\ Beijing Institute of Spacecraft Environment Engineering, Beijing, China
}

\begin{abstract}
A large-scale cryopump (DN1250 $\left.\mathrm{LN}_{2}\right)$ used in space environment simulation system was designed and its performance experimentally investigated by BISEE. In the design, the cryopanels of the cryopump were cooled by Brooks Model 1020 cold head which with high second stage cooling capacity of about 12W @ 20K. The thermal radiation shield and baffle were cooled by liquid nitrogen. A design method for three main technical data (pumping speed for $\mathrm{N}_{2}$, cool down time and crossover) of the pump was introduced in this paper. A test system according to the test standards for cryopump (JB/T 11081-2011) was built to test main performance of the cryopump. The experimental results showed that the pumping speed for $\mathrm{N}_{2}$ of the pump was up to $57,000 \mathrm{~L} / \mathrm{s}$, the cool down time was about $330 \mathrm{~min}$, and the crossover was over than $3.0 \times 10^{5} \mathrm{~Pa} \cdot \mathrm{L}$.
\end{abstract}

KEYWORD: Cryopump; Pumping speed for $\mathrm{N}_{2}$; Cool down time; Crossover

\section{INTRODUCTION}

A large-scale cryopump (DN1250 $\left.\mathrm{LN}_{2}\right)$ used in space environment simulation system was designed and its performance experimentally investigated by Beijing Institute of Spacecraft Environment Engineering (BISEE). There are a number of advantages of this kind of cryopump as simple structure, oil free, high pumping rate of condensable gas, high ultra-vacuum pressure, wide range of working pressure and easy to operate \& maintain etc[1]. For these reasons, cryopump was wildly used in space environment simulation system as highvacuum pump.

In this paper, a design method for three main technical data (pumping speed for $\mathrm{N}_{2}$, cool down time and crossover) of the cryopump was introduced. A test system according to the test standards for cryopump (JB/T 11081-2011) was built to test main performance of the cryopump. The experimental results were showed at the end of the paper.

\section{RESEARCH METHODOLOGY}

\subsection{Configuration and function of the cryopump}

Cryopump pumping gas by very cold panels which was cooled by Brooks Model 1020 cold head which with high second stage cooling capacity of about 12W@20K. The thermal radiation shield and baffle were cooled by liquid nitrogen.

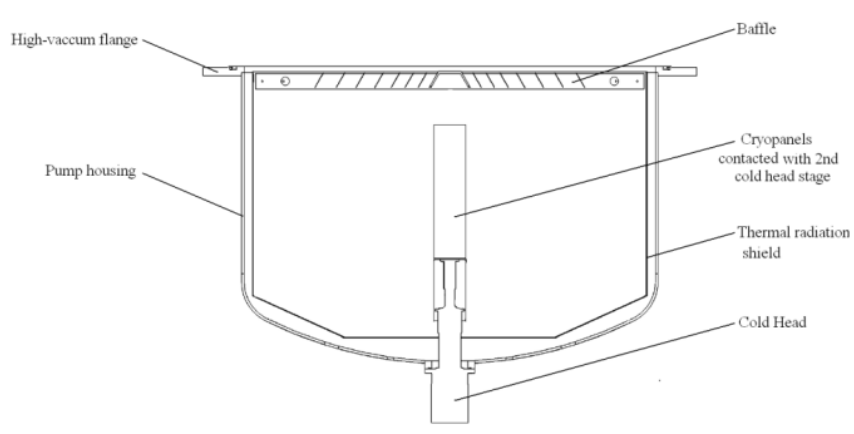

Figure 1. The diagram of the inside of the cryopump



Figure 2. The photograph of the DN1250 $\mathrm{LN}_{2}$ cryopump 
Three methods were used in cryopump to absorb gas inside the vacuum chamber to achieve vacuum pumping, which are cryocondensation, cryosorption, and cryotrapping, of which cryocondensation and cryosorption are the primary methods[2]. The thermal radiation shield and baffle, which will condense and cool water vapor and most hydrocarbons at temperatures below $100 \mathrm{~K}$. The low temperatures for the cryopanels were generated in a cold head and compressor unit. The cold head cools the cryopanels to $\leq 12 \mathrm{~K}$. The second stage of the cold head was contacted to the cryopanels. The first stage was not contacted to the cryopump. Virtually all other gases condense on the outer surfaces of the cryopanels. The gases hydrogen, helium and neon were trapped into the activated charcoal on the inner surfaces of the cryopanels.

\subsection{The design method of the cryopump for main technical data}

\subsubsection{Pumping Speed for $\mathrm{N}_{2}$}

For DN1250 $\mathrm{LN}_{2}$ cryopump, the pumping speed[3] for $\mathrm{N}_{2}$ can be calculated as the following equations.

$$
S=S_{t h} \cdot \alpha \cdot A_{1}
$$

Where $S$ = pumping speed of the cryopump; $\alpha=$ cryocondensation coefficient; $A_{1}=$ the exterior surface of the cryopanels; and $S_{t h}=$ the maximum pumping speed on the unit area of the exterior surface of the cryopanels.

$$
S_{t h}=3.638 \sqrt{\frac{T_{N 2}}{M}}
$$

Where $T_{N 2}=$ The temperature of $\mathrm{N}_{2} ; M=$ The molecular weight of $\mathrm{N}_{2}$.

\subsubsection{Cool down time}

In the design of DN1250 $\mathrm{LN}_{2}$ cryopump, consider that the pressure in the cryopump was less than $10^{-1}$ $\mathrm{Pa}$ before the cryopump cools down, the conduction and the convection and the latent heat of the gas condensation could be ignored. Thus the heat of the cryopanels was divided into three parts: The heat provided by the second stage of the cold head $Q_{1}$; The radiant heat of the thermal radiation shield and baffle $Q_{2}$; And the leak heat $Q_{3}$. The heat in effect of the cryopanels could be expressed as the following equation.

$$
Q_{\text {eff }}=Q_{1}+Q_{2}+Q_{3}
$$

Where $Q_{1}=$ the heat provided by second stage of the cold head, the value could be got by Figure 3 . which was provided by Brooks.

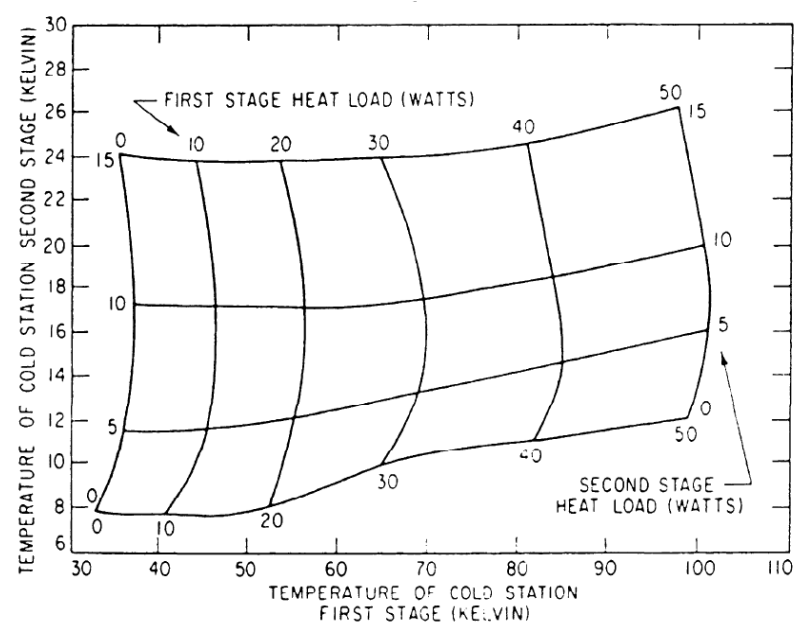

Figure 3. The cold power of the cold head( Model-1020)

$Q_{2}$ was the radiant heat of the thermal radiation shield and baffle.

$$
Q_{2}=\frac{5.67 A_{1}\left[\left(\frac{T_{2}}{100}\right)^{4}-\left(\frac{T_{1}}{100}\right)^{4}\right]}{\frac{1}{\varepsilon_{1}}+\frac{A_{1}}{A_{2}}\left(\frac{1}{\varepsilon_{2}}-1\right)}
$$

Where $A_{2}=$ the inner surface of the thermal radiation shield and baffle; $\varepsilon_{1}=$ the emissivity of the exterior surface of the cryopanels; $\varepsilon_{2}=$ the emissivity of the inner surface of the thermal radiation shield and baffle; $T_{1}=$ the temperature of the cryopanels; $T_{2}=$ the temperature of the thermal radiation shield and baffle.

$Q_{3}$ was the leak heat of the cryopump.

$$
Q_{3}=\sigma \cdot A_{1} \cdot \varepsilon_{1} \cdot l\left[\left(\frac{T_{h}}{100}\right)^{4}-\left(\frac{T_{1}}{100}\right)^{4}\right]
$$

Where $\sigma=$ Stefan Boltzmann's constant; $l=$ heat leak rate; $T_{h}=$ the temperature of the pump housing.

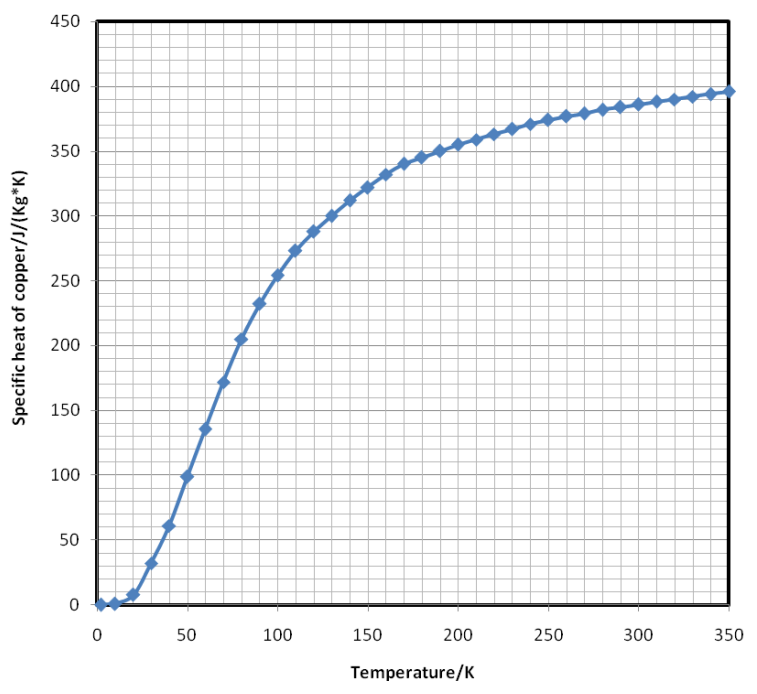

Figure 4. The specific heat $c$ of copper

Consider that the specific heat $c$ of the copper (the material of the cryopanels) was the function of the temperature $T$ of the cryopanels, as shown in 
Figure 3. The cool down time $t$ of the cryopump was considered as the following equation.

$$
t=m \int_{T_{c}}^{T_{a}} \frac{c(T)}{Q_{\text {eff }}(T)} d T
$$

Where $m=$ the mass of the cryopanels; $T=$ Temperature; $T_{a}=$ init temperature of the cryopanels; $T_{c}=$ the terminal temperature of the cryopanels which could be calculated by Eq. (7); $c(T)=$ the specific heat of cooper at temperature $T$; $Q_{\text {eff }}(T)=$ the heat in effect of the cryopanels at temperature $T$.

When the cryopump achieve thermal equilibrium,

$$
Q_{\text {eff }}=0
$$

The terminal temperature $T_{c}$ could be got from Figure 3.

\subsubsection{Crossover}

In cryopump, the crossover was defined by the maximum amount of nitrogen gas (in $\mathrm{Pa} \cdot \mathrm{L}$ ) which could be admitted to the cryopump over a short time with the temperature of the second stage remaining at or below 20K during the test gas flow [4].

For DN1250 $\mathrm{LN}_{2}$ cryopump, the heat of condensation of the DN1250 $\mathrm{LN}_{2}$ cryopump could be expressed as following equation.

$$
Q_{c, N_{2}}=Q_{0, c}
$$

Where $Q_{c, N 2}=$ The heat of condensation of the DN1250 $\mathrm{LN}_{2}$ cryopump; $Q_{0, c}=$ The heat of the cryopanels and the cold head from the terminal temperature up to $20 \mathrm{~K}$.

The saturation vapor pressure of liquid nitrogen versus temperature was shown as Figure 5.

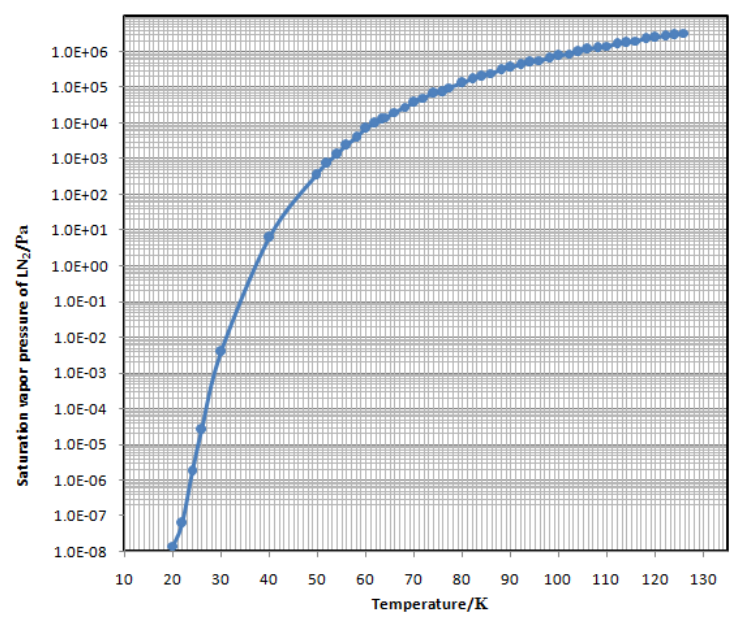

Figure 5. Saturation vapor pressure of $\mathrm{LN}_{2}$

At $20 \mathrm{~K}$, saturation vapor pressure of $\mathrm{LN}_{2}$ was approximate $1.44 \times 10^{-8} \mathrm{~Pa}$, under this condition, the left hand in Eq.(8) could be divided into two parts: $\mathrm{N}_{2}$ cool down from room temperature to temperature of the cryopanels $Q_{r}$; And the heat of $\mathrm{N}_{2}$ solidification $Q_{\mathrm{s}}$.

$$
Q_{c, N_{2}}=Q_{r t}+Q_{s}
$$

Where,

$$
Q_{r t}=\int_{T_{r}}^{T_{c r}} m_{N_{2}} c_{N_{2}}(T) d T
$$

Where $T_{r}=$ the room temperature; $T_{c r}=$ the maximum temperature of the cryopanels when test the crossover; $m_{N 2}=$ the mass of $\mathrm{N}_{2} ; c_{N 2}(T)=$ the specific heat of $\mathrm{N}_{2}$ at temperature $T ; Q_{s}=$ the latent heat of the $\mathrm{N}_{2}$ solidification.

If ignore the effect of the temperature uniformity of the cold head and the cryopanels, the right hand in Eq. (8) could be expressed as follows.

$$
Q_{o, c}=m \int_{T_{c}}^{T_{c r}} c(T) d T
$$

\section{TEST SYSTEM FOR CRYOPUMP}

The test system was shown in Figure 2. The system was consisted of cryopump, dry pump, test dome, vacuum gauge, gas flow meter, and valve etc [5-6]. The Pirani gauge, Bayard-Alpert gauge and gas flow meter were sent to Beijing Aerospace Institute for Metrology and Measurement Technology for $\mathrm{N}_{2}$ calibration prior to the experiment. The silicon diode sensor and cryogenic temperature monitor were sent to Center of Cryogenic Metrology (Technical Institute of Physics and Chemistry, CAS). Four silicon diode sensors were installed separately on the Baffle and the cryopanels. Three PT-102 sensors were installed separately on the thermal radiation shield. To simplify the display for the temperature of the second stage and the Baffle and the radiation shield the temperature curves illustrated for this study were average means measured by the sensors. The test dome was constructed according to the test standards for the cryopump JB/T 11081-2011.This paper uses flow meter method to investigate the pumping characteristics of the cryopump under different gas flow rates.

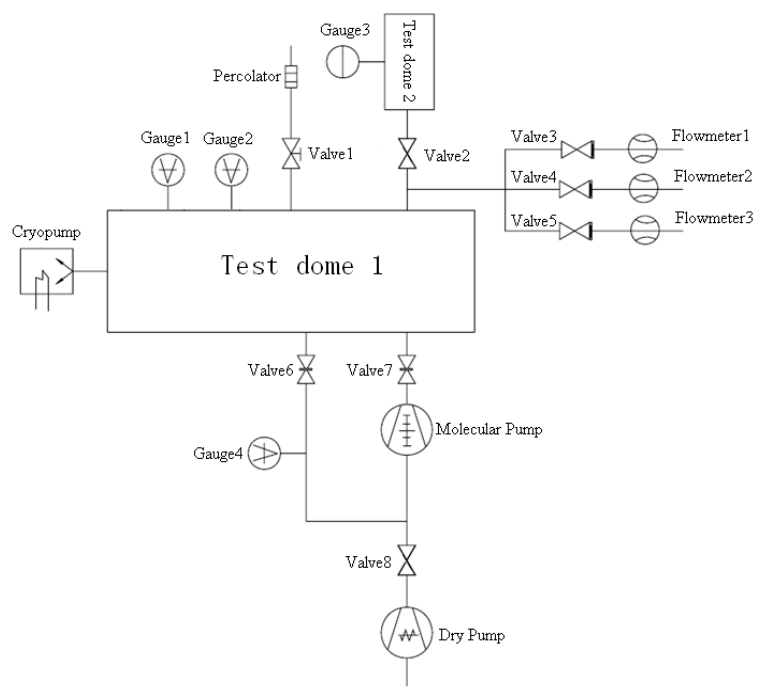

Figure 6. The test system for cryopumps 


\section{RESULTS AND DISCUSSIONS}

Figure 7. shows the pumping speed relative to the pressure. The test curves above show that pumping speed constant from the magnitude of $10^{-4} \mathrm{~Pa}$ to $10^{-}$ ${ }^{3} \mathrm{~Pa}$, but during the magnitude of $10^{-2} \mathrm{~Pa}$, the pumping speed increases. The value of the pumping speed for the cryopump was about $57500 \mathrm{~L} / \mathrm{s}$ to $58000 \mathrm{~L} / \mathrm{s}$, which can be seen as a constant.

Figure 8. shows the cryopanels temperature and the temperature of the buffer and the radiation shield relative to the operating time. The cool down time to $20 \mathrm{~K}$ was about $330 \mathrm{~min}$.

Figure 9. shows the cryopanels temperature relative to the time when test the crossover. The crossover value was $3.0153 \times 10^{5} \mathrm{~Pa} \cdot \mathrm{L}$, the gas in test dome 2 should be admitted within $3 \mathrm{~s}$. The curve shows that the temperature of second cold head rises to $19.7 \mathrm{~K}$ from $12 \mathrm{~K}$, but for no more than 10 minutes the temperature went back to about $12 \mathrm{~K}$, and the cryopump reached its normal operating mode again. The results showed the crossover value of the cryopump tested was about $3.0 \times 10^{5} \mathrm{~Pa} \cdot \mathrm{L}$.

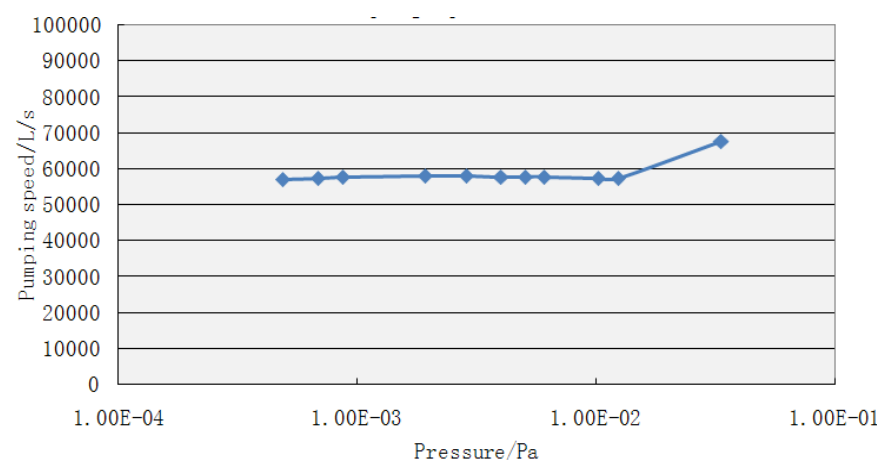

Figure 7. Pumping speed test result of DN1250LN $\mathrm{L}_{2}$ cryopump

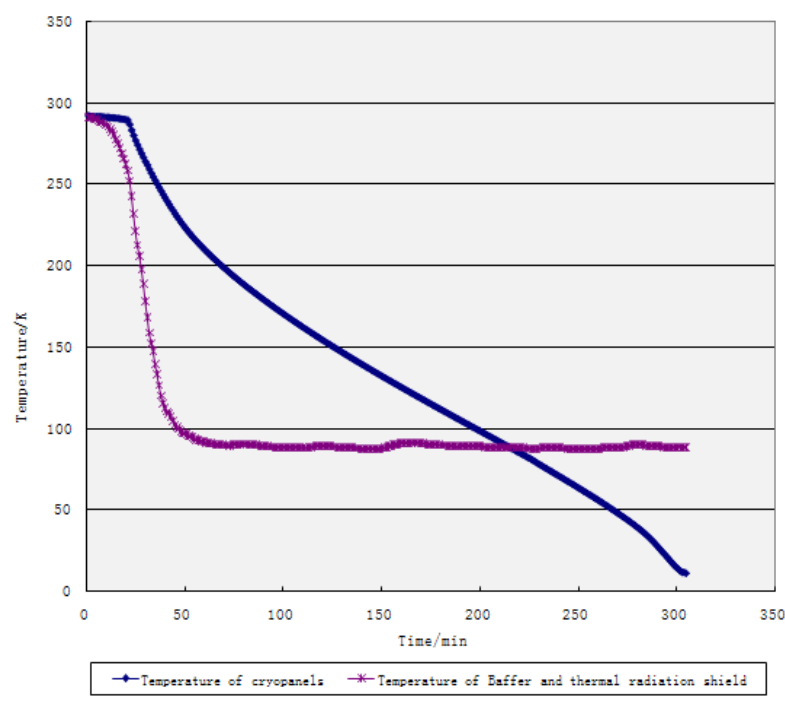

Figure 8. Cool down time test result of DN1250LN 2 cryopump

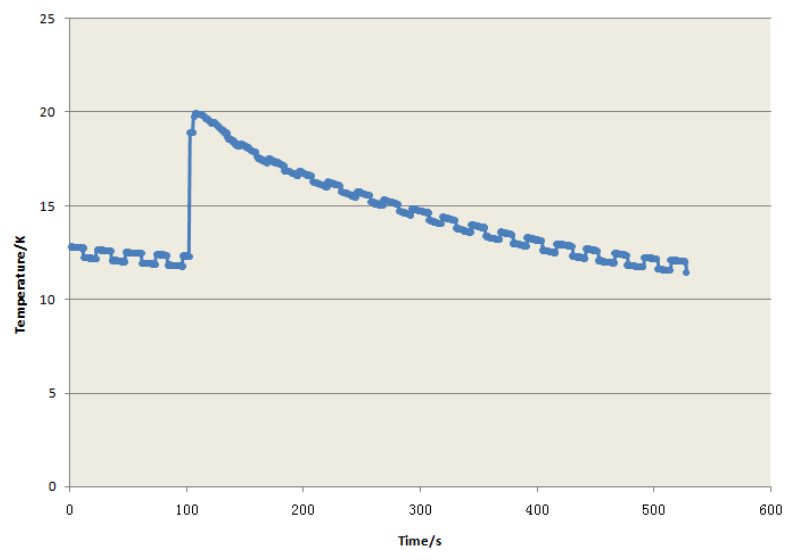

Figure 9. Crossover test result of DN1250LN 2 cryopump

\section{CONCLUSIONS}

A design method for three main technical data (pumping speed for $\mathrm{N}_{2}$, cool down time and crossover) of the cryopump was introduced in this paper. The method was validated by the main performance test of $\mathrm{DN} 1250 \mathrm{LN}_{2}$ cryopump. The pumping speed (for $\mathrm{N}_{2}$ ) was up to $57,000 \mathrm{~L} / \mathrm{s}$, the cool down time was about 330min, and the crossover was over than $3.0 \times 10^{5} \mathrm{~Pa} \cdot \bullet \mathrm{L}$. All the performance was satisfied the target of the design and the cryopump was successful used in space environment simulation system.

\section{ACKNOWLEDGMENT}

The authors are thankful to all staff of Vacuum and Leak Test Division of BISEE, particularly to staff involved in the development of cryopump.

\section{REFERENCES}

[1] S G Gilankar, 2008. Experimental Verification of Capture Coefficients for a Cylindrical Cryopanel of Closed Cycle Refrigerator Cryopump. Journal of Physics: Conference Series, 2008.

[2] Kimo M Welch, 1999, Recommended practices for measuring the performance and characteristics of closedloop gaseous helium cryopumps. Journal of Vacuum Science and Technology A, 17(5):3081-3095.

[3] Baechler, W. G. 1987. Cryopumps for research and industry. Vacuum 37(1-2): 21-29.

[4] Häfner, H. U., H. H. Klein, et al. 1990. New methods and investigations for regenerating refrigerator cryopumps. Vacuum 41(7-9): 1840-1842.

[5] Ikegami, K., S. Nakajima, et al. 1988. Design and performance characteristics of refrigerator-cooled cryopumps for the RIKEN ring cyclotron. Vacuum 38(2): 99-102.

[6] Juhnke, C., H. H. Klein, et al. 1993. The crossover of refrigerator-cooled cryopumps. Vacuum 44(5-7): 717-719. 